\title{
Diversity of group A rotavirus of porcine rotavirus in Shandong province China
}

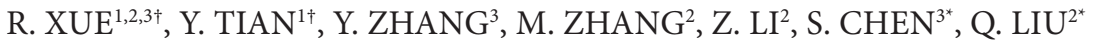 \\ ${ }^{1}$ College of Animal Science and Technology, Shandong Agriculture University, Taian, Shandong, P. R. China; ${ }^{2}$ Shanghai Veterinary \\ Research Institute, CAAS, Shanghai, P. R. China; ${ }^{3}$ Shandong Provincial Center for Animal Disease Control and Prevention, Jinan, \\ Shandong, P. R. China
}

Received August 21, 2017; revised January 3, 2018; accepted June 29, 2018

\begin{abstract}
Summary. - Porcine rotavirus (PoRV) is one of the major causes of neonatal diarrhea in swine worldwide. Multiple serotypes of PoRV have been detected in diarrhea cases of suckling and weaning pigs. To date, the prevalence and molecular characterizations of PoRV circulating in swine in Shandong province of China remains largely unknown. Two hundred and twenty-six feces samples were collected from ten farms showing diarrhea in Shandong. All the samples were tested by RT-PCR for the presence of PoRV, TGEV, or PEDV. The results showed that all farms are positive for PEDV, and $60 \%$ and $10 \%$ of the farms are positive for PoRV and TGEV respectively. PoRV was detected in 65 out of 226 (28.76\%) samples collected from 1-3 months old suckling and weaning pigs, while the positive rates of the TGEV and PEDV were $2.21 \%$ and $34.96 \%$, respectively. The present data emphasized that PoRV is an important pathogen causing diarrhea in swine in China. In addition, VP6 and VP7 genes of PoRVs were sequenced and analyzed. Phylogenetical analysis of VP6 showed that all of the five PoRVs belong to group A rotavirus, meanwhile VP7 genes belong to the G3, G5, and G9 genotypes. Moreover, G5 and G9 genotypes are the dominant genotypes. Taken together, co-infections of TGEV, PEDV, and PoRV occur in pig population in Shandong, and the multiple serotypes of PoRVs are circulating in those herds, suggesting the active surveillance and matched vaccine application.
\end{abstract}

Keywords: rotavirus; diarrhea; piglet; VP6; VP7; Shandong

\section{Introduction}

Diarrhea of piglets, induced by bacteria, viruses, or parasites, is a severe infectious syndrome, which often occurs in winter and spring and causes serious economic losses. Rotaviruses are an important etiologic agent of severe diarrhea among infants and young children, as well as the young of many species of animals. For instance, the bovine rotavirus was isolated from cattle worldwide (Hayashi-Miyamoto et al., 2017; Papp et al., 2013). The human rotavirus was found in humans by Bishop et al. (1979), and in the next year the

"Corresponding authors. E-mail: csm7034@sina.com (S. Chen), liuqinfang@shvri.ac.cn (Q. Liu); phone: +8653187106962, +8613524 590796. 'These authors contributed equally to this work.

Abbreviations: $\mathrm{PoRV}=$ porcine rotavirus; $\mathrm{PEDV}=$ porcine epi demic diarrhea virus; $\mathrm{RVA}=$ group $\mathrm{A}$ rotavirus; $\mathrm{TGEV}=$ transmis sible gastroenteritis virus porcine rotavirus was isolated from infected pigs by Woode $e t$ al. (1976). The piglets infected with porcine rotavirus (PoRV) show anorexia, restlessness, and occasional vomiting after the incubation period of 12-14 h. Even more, piglets suffers from high-capacity watery diarrhea, which not only leads to slow-growth in piglets, but also causes high mortality (Vlasova et al., 2017).

Rotaviruses, members of the family Reoviridae, are nonenveloped icosahedral particles. Rotaviruses have been classified into eight groups $(\mathrm{A}-\mathrm{H})$ and two subgroups (I and II) based on the antigenic determinants of VP6 gene (Matthijnssens et al., 2012). Among them, strains in group A, B, $\mathrm{C}$, and $\mathrm{H}$ could infect humans and many other animal species (Wakuda et al., 2011); nevertheless, strains in group D, E, F, and $\mathrm{G}$ have only been found in birds and pigs (Johne et al., 2011). Five PoRV groups (RVA, RVB, RVC, RVE, and RVH) have been detected in pigs (Wakuda et al., 2011), among these groups, group A rotavirus (RVA) is considered the 
most important in intestinal disease. RVA in piglets causes economic loses to swine industry worldwide. In UK, RVA positive samples rate reached $80 \%$ in fecal samples in 2009 and 2010 (Chandler-Bostock et al., 2015). Molinari et al. (2016) reported that $61 \%$ of tested pig farms with diarrhea symptom were RVA and/or RVC positive in Belgium (Theuns et al., 2016). In Brazil, $46 \%$ diarrhea samples from pigs were RVA positive (Molinari et al., 2016).

The genome of rotaviruses is composed of 11 segments of double-stranded RNA encoding six structural proteins (VP1-VP4, VP6, and VP7) and five non-structural proteins (NS53, NS35, NS34, NS28, and NS26). VP6 gene encodes intermediate capsid protein which plays an important role in virus replication. Meanwhile, VP6 protein is the main determinant of species specificity. VP7 gene encodes outercapsid glycoprotein (Mukherjee et al., 2009). It is the main immunogen that induces neutralizing antibodies (Santos et al., 2005). Rotavirus genotypes are very diverse, and among which, VP7 gene determines G-genotype (Estes and Cohen, 1989). Rotavirus strains within one G-genotype shares at least 90-91\% VP7 amino acid sequence identity (Ciarlet et al., 2002). To date, there is 27 G-genotypes that have been identified from many species (Matthijnssens et al., 2011; Trojnar et al., 2013). Until now, 12 G-genotypes (G1 to G6, G8 to G12, and G26) have been found in symptomatic and asymptomatic infections (Martella et al., 2010; Papp et al., 2013).

Shandong Province has the biggest swine industry in China, however, the prevalence and molecular characterization of PoRV circulating in swine in Shandong remains largely unknown.

\section{Materials and Methods}

Sample collection. Piglet diarrhea feces samples were collected from October 2013 to October 2014 from ten pig farms with diarrhea symptoms located in different areas in Shandong. A total of 226 piglet fecal samples were collected from diseased pigs in ten farms located in different cities in Shandong Province (Table 1)

Table 1. Detection rates of PoRV, PEDV, and TGEV in fresh feces collected from suckling and weaning pigs from ten farms located in different cities of Shandong province

\begin{tabular}{|c|c|c|c|c|c|c|c|}
\hline \multirow{2}{*}{ Farms } & \multirow{2}{*}{$\begin{array}{c}\text { Total } \\
\text { samples }\end{array}$} & \multicolumn{3}{|c|}{ Number of positive sample } & \multirow{2}{*}{$\begin{array}{l}\text { PEDV and PoRV } \\
\text { co-infection }\end{array}$} & \multirow{2}{*}{ Number of pigs } & \multirow{2}{*}{ Age } \\
\hline & & TGEV & PEDV & PoRV & & & \\
\hline Dezhou & 31 & 0 & 5 & 5 & 2 & 800 & 3-4 weeks \\
\hline Jinan & 38 & 5 & 8 & 9 & 0 & 1000 & 4 weeks \\
\hline Jining & 33 & 0 & 7 & 10 & 2 & 600 & 5-6 weeks \\
\hline Linyi & 17 & 0 & 10 & 5 & 1 & 500 & 3 weeks \\
\hline Taian & 36 & 0 & 12 & 23 & 1 & 600 & 4 weeks \\
\hline Binzhou & 10 & 0 & 3 & 0 & 0 & 200 & 7 weeks \\
\hline Weifang & 48 & 0 & 27 & 13 & 1 & 1300 & 5-7 weeks \\
\hline Rizhao & 5 & 0 & 2 & 0 & 0 & 400 & 5 weeks \\
\hline Dongying & 5 & 0 & 3 & 0 & 0 & 300 & $3-5$ weeks \\
\hline Liaocheng & 3 & 0 & 2 & 0 & 0 & 500 & 5 weeks \\
\hline Total & 226 & 5 & 79 & 65 & 7 & 6200 & \\
\hline Positive rate (\%) & & $2.21 \%$ & $34.96 \%$ & $28.76 \%$ & $3.10 \%$ & & \\
\hline
\end{tabular}

Table 2. Sequence of primers designed to detect PEDV, TGEV, and PoRV

\begin{tabular}{llc}
\hline Primer name & Sequence $\left(\mathbf{5}^{\prime} \rightarrow \mathbf{3}^{\prime}\right)$ & Size $(\mathbf{b p})$ \\
\hline PEDV-F & CCGAGTGCGGTTCTCACAGA & 1370 \\
PEDV-R & CATAGCCAGGATAAGCCGGT & N \\
TGEV-F & AGAACGCTATTGTGCTAT & 697 \\
TGEV-R & TCTTGCCTCTGTTGAGTA & M \\
PoRV-F & GGCTTTTAAACGAAGTCTTC & 1062 \\
PoRV-R & GGTCACATCCTCTCACTA & 876 \\
PoRV-VP4F & TCCATGGCTTCGCTCATTTATAGACA & VP6 \\
PoRV-VP4R & GAGTAACCTCGAGGACCATTTATAACCCAAT & 1026 \\
PoRV-VP7F & GGCTTTAAAAGAGAGAATTTC & VP4 \\
PoRV-VP7R & GGTCACATCATACAGTTCTAAC & VP7 \\
\hline
\end{tabular}




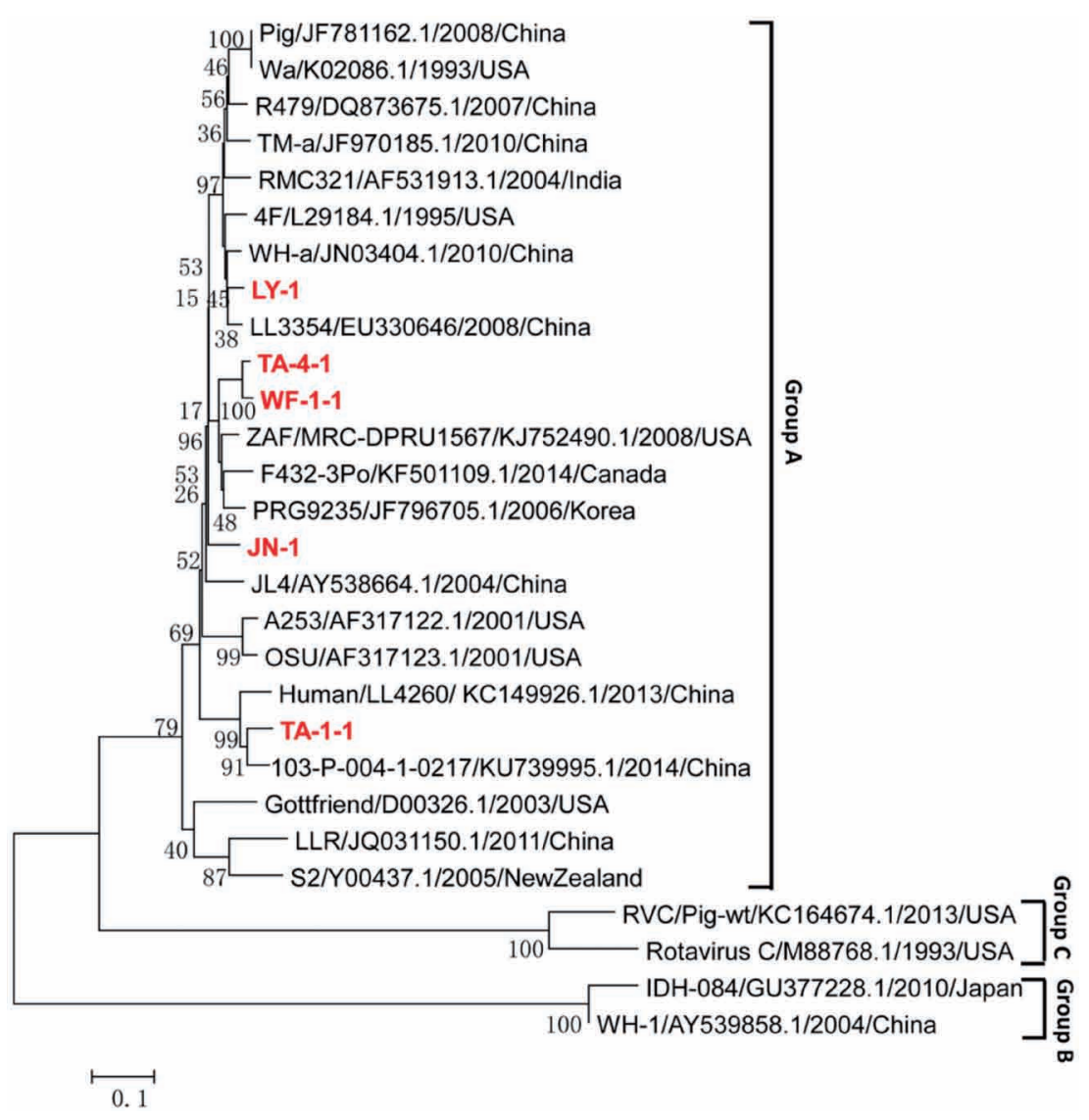

Fig. 1

Phylogenetic tree based on the nucleotide sequences of VP6 genes from different porcine rotavirus strains The viruses isolated in this study are in bold and red. The names of strains are given: strain name/accession number/year/country. The scale represents genetic distance.

from October 2013 to October 2014. The animals were up to three weeks old and showed diarrhea of various severity. The samples were diluted in ratio of 1:5 with phosphate-buffered saline (PBS), and centrifuged at 5,000 x g for $10 \mathrm{~min}$. The supernatants were collected for further analysis.

RNA isolation and RT-PCR. Viral RNA was extracted from fecal specimens using TRIzol $^{\circledR}$ reagent according to manufacturer's instructions (Thermo Fisher, USA). One-step RT-PCR (Takara, Japan) was conducted in reaction mixtures consisting of $1 \mu \mathrm{l}$ RA, $2 \mu$ of Prime Script ${ }^{\oplus}$ One Step enzyme mix, $1 \mu$ of forward and reverse primer $(20 \mu \mathrm{mol} / \mathrm{l}), 12.5 \mu \mathrm{l}$ of $2 \times$ one-step buffer, and nuclease free water in a total volume of $25 \mu \mathrm{l}$ per reaction. The RT-PCR conditions involved an initial reverse transcription of $30 \mathrm{~min}$ at $50^{\circ} \mathrm{C}$, followed by PCR activation at $95^{\circ} \mathrm{C}$ for $10 \mathrm{~min}, 32$ cycles of amplification $\left(1 \mathrm{~min}\right.$ at $94^{\circ} \mathrm{C}, 30 \mathrm{~s}$ at $53^{\circ} \mathrm{C}$ and $30 \mathrm{~s}$ at $72^{\circ} \mathrm{C}$ ) with final extension at $72^{\circ} \mathrm{C}$ for $10 \mathrm{~min}$. All RT-PCR products were analyzed on $0.8 \%$ agarose gel containing $0.5 \mu \mathrm{g} / \mathrm{ml}$ ethidium bromide and visualized under UV transilluminator.

Primers. To detect the three pathogens, three pairs of specific primers were designed to detect porcine epidemic diarrhea virus
(PEDV) targeting $\mathrm{N}$ gene, transmissible gastroenteritis virus (TGEV) targeting M gene, and PoRV targeting VP6 gene from the samples. Another two pairs of primers targeting VP7 and VP4 genes of PoRV were designed and were used to amplify the fulllength gene segments for further analysis. All primer sequences are summarized in Table 2.

Genotyping. To identify the genotypes of swine PoRV strains, the VP4, VP6, and VP7 were amplified and the PCR products were purified and cloned into pMD $^{\circ} 18-\mathrm{T}$ (Takara, Japan). VP4, VP6, and VP7 genes were sequenced by sequencing center in Shandong Academy of Agriculture Science. The sequences were assembled and edited using MEGA 6 software (Drummond and Rambaut, 2007). The nucleotide sequences derived in the present study were deposited in GenBank (KT820766 to KT820783). Molecular analysis was conducted by comparing the nucleotide sequences of VP4, VP6, and VP7 genes with those of reference strains available from GenBank. Alignments of multiple sequences were performed using the CLUSTAL W by MEGA 6 software. Phylogenetic trees were constructed via neighbor-joining method with 1,000 bootstrap replications. 


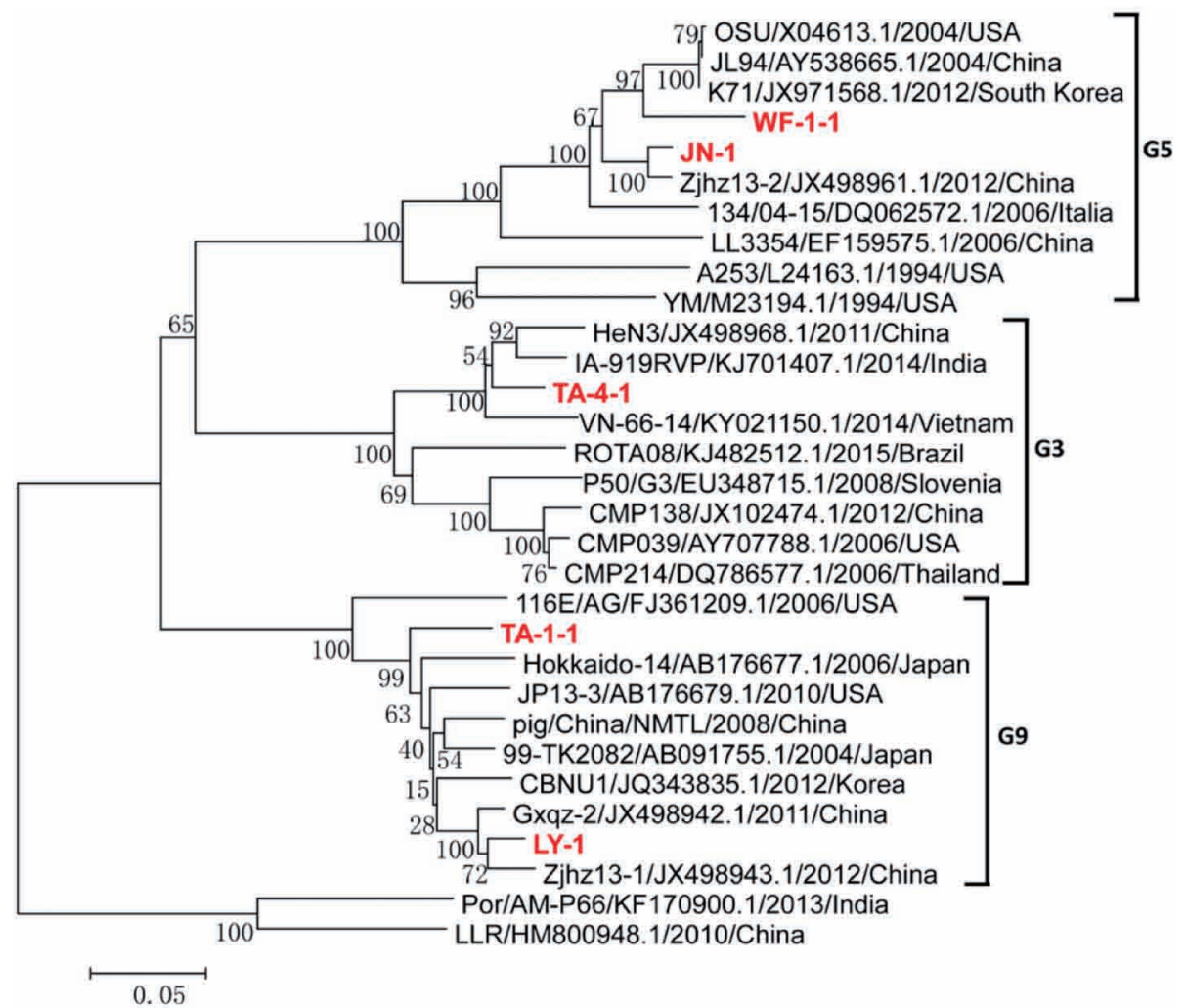

Fig. 2

Phylogenetic tree based on the nucleotide sequences of VP7 genes from different porcine rotavirus strains The viruses isolated in this study are in bold and red. The names of strains are given: strain name/accession number/year/country. The scale represents genetic distance.

Results

\section{Surveillance}

The surveillance results showed that PoRV was identified in 65 out of $226(28.76 \%)$ samples collected from $1-3$ months old suckling and weaning pigs. The positive rates of TGEV and PEDV were 2.21\% (5/226) and 34.95\% (79/226), respectively. Furthermore, all investigated farms were positive for PEDV, and $60 \%$ and $10 \%$ of the farms were positive for PoRV and TGEV, respectively. Moreover, the positive rate of PoRV of one farm (Taian) was as high as $63.38 \%$ (Table 1). Our data for the first time indicated that PoRV tends to be the second most important pathogen causing diarrhea in swine in Shandong besides PEDV. In addition, 3.10\% of the samples were positive for both PEDV and PoRV, suggesting the co-infection of these two pathogens among the pigs. However, the positive rate of TGEV was lower than the other two pathogens.

The presence of PoRV RNA in five positive samples (termed as LY-1, TA-1-1, TA-4-1, WF-1-1, JN-1) was confirmed by sequencing of VP4, VP6, and VP7 genes. The nucleotide sequences derived in the present study were deposited in GenBank with Acc. Nos. of KT820766 to KT820783.

\section{Genotyping}

The VP6 deduced amino acid sequence homologies among five rotavirus isolates ranged from $91.20 \%$ to $99.0 \%$, and all isolates shared high similarities of $87.40 \%$ to $99.50 \%$ with the PoRV from group A, and lower identities with group C (35.0\% to $41.20 \%)$ and group B (10.20\% to $11.0 \%)$. Similarly, phylogenetic analysis showed that five rotavirus isolates were located in group A, suggesting that all the isolates belong to PoRV group A (Fig. 1).

Based on phylogenetic analysis and alignment of the five VP7 gene sequences with representative strains, the VP7 deduced amino acid sequence identities among five rotavirus isolates ranged from $81.3 \%$ to $99.7 \%$. WF-1-1 and JN-1 strains showed high range of similarities (93.90\% to 99.10\%) with G5 representative strains (Fig. 2). LY-1 and TA-1-1 strains were clustered together with G9 reference strains $(94.5 \%$ to $98.5 \%)$. It is interesting to point out that TA-4-1 strain, which was isolated from the same region as TA-1-1, was more closely related to G3 representative strains (93.60\%) than to G9 strains (86.50\% to $87.50 \%$ ) (Fig. 2).

Based on phylogenetic analysis and alignment of VP4 gene sequences with representative strains, the VP4 de- 


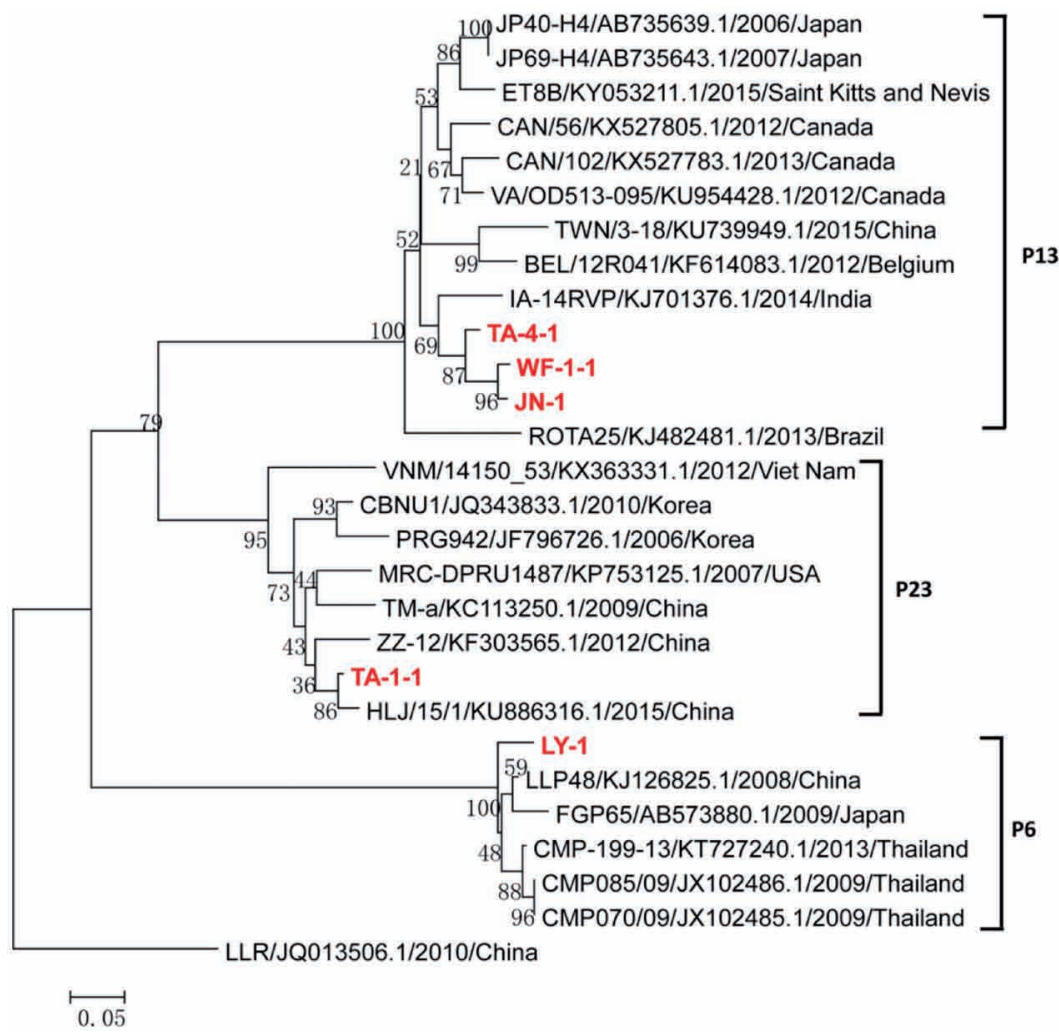

Fig. 3

Phylogenetic tree based on the nucleotide sequences of VP4 genes from different porcine rotavirus strains

The viruses isolated in this study are in bold and red. The names of strains are given: strain name/accession number/year/country. The scale represents genetic distance.

duced amino acid sequence identities among five rotavirus isolates ranged from $81.3 \%$ to $99.7 \%$. Phylogenetic trees indicated that TA-4-1, WF-1-1, and JN-1 strains showed close relationship with P13 representative strains (Fig. 3). TA-1-1 strains were clustered together with P23 reference strain, and LY-1 was more closely related to P6 representative strain (Fig. 3).

\section{Discussion}

PoRV is one of the main pathogens of porcine diarrhea, however, it is difficult to differentiate it from PEDV and TGEV only by clinical signs. PoRV not only causes diarrhea, but also inhibits the immune system, resulting in growth arrest and mortality increase in piglets. In this study, $100 \%$ of the investigated farms are positive for PEDV, $10 \%$ and $60 \%$ of the farms are positive for TGEV and PoRV, respectively. Additionally, $28.76 \%$ and $34.95 \%$ of the collected samples are positive for PoRV and PEDV, respectively. PEDV is a major pathogen causing diarrhea in swine in China, however, the circulation situation of PoRV remains largely unclear. Our data are the first to indicate that PoRV seems to be the second important pathogen causing diarrhea in swine in China.

VP6 is an important group antigen of PoRV, associated with VP4 and VP7 to constitute the framework of the virus. Through phylogenetic analysis, all of the five isolated viruses were located in the same branch with group A viruses. The results showed that, during the year of 2013 and 2014, group A rotaviruses were the epidemic group circulating in pig herds in Shandong Province.

VP7 gene is the main immune protective antigen, which not only stimulates the body to produce antibodies but also determines the G-genotype of PoRV (Kim et al., 2013). Previous studies suggest that highly variable area is located in VP7 genetic region (Coulson and Kirkwood, 1991). The antigenic site encoded by VP7 gene has little cross protection among different genotypes (Diwakarla and Palombo, 1999).

This study revealed that multiple genotypes of PoRV are circulating in Shandong, China. For instance, the WF-5-2 strain isolated from Weifang region belongs to G5 genotype, but LY-2 strain belongs to G9 genotype which was isolated from Linyi region. Interestingly, the PoRV isolated from the Taian region belongs to different genotype, such as the TA-1-2 and TA-4-2 strains isolated from the same place of 
Taian region belonging to genotype G9 and G3. Therefore, vaccines should be used rationally depending on different genotypes circulating in different regions.

Acknowledgments. This study was supported by the National Natural Science Foundation of China (No.31772753, No. 31572543, No. 31472206 and No. 31402150), and Chinese Academy of Agricultural Sciences Young Talent Scientist Program (No. CAASQNYCKYYJ58), Epidemiological Survey of Diarrhea Piglet and Study of Synthesize Control of Shandong Province (No. 2013GC15003).

\section{References}

Bishop RF, Cameron DJ, Veenstra AA, Barnes GL (1979): Diarrhea and rotavirus infection associated with differing regimens for postnatal care of newborn babies. J. Clin. Microbiol. $9,525-529$.

Chandler-Bostock R, Hancox LR, Payne H, Iturriza-Gomara M, Daly JM, Mellits KH (2015): Diversity of group A rotavirus on a UK pig farm. Vet. Microbiol. 180, 205-211. https://doi.org/10.1016/j.vetmic.2015.09.009

Ciarlet M, Hyser JM, Estes MK (2002): Sequence analysis of the VP4, VP6, VP7, and NSP4 gene products of the bovine rotavirus WC3. Virus Genes 24, 107-118. https://doi. org/10.1023/A:1014512314545

Coulson BS, Kirkwood C (1991): Relation of VP7 amino acid sequence to monoclonal antibody neutralization of rotavirus and rotavirus monotype. J. Virol. 65, 5968-5974.

Diwakarla CS, Palombo EA (1999): Genetic and antigenic variation of capsid protein VP7 of serotype G1 human rotavirus isolates. J. Gen. Virol. 80 (Pt 2), 341-344. https://doi. org/10.1099/0022-1317-80-2-341

Drummond AJ, Rambaut A (2007): BEAST: Bayesian evolutionary analysis by sampling trees. BMC Evol. Biol. 7, 214. https:// doi.org/10.1186/1471-2148-7-214

Estes MK, Cohen J (1989): Rotavirus gene structure and function. Microbiol Rev. 53, 410-449.

Hayashi-Miyamoto M, Murakami T, Minami-Fukuda F, Tsuchiaka S, Kishimoto M, Sano K, Naoi Y, Asano K, Ichimaru T, Haga K, Omatsu T, Katayama Y, Oba M, Aoki H, Shirai J, Ishida M, Katayama K, Mizutani T, Nagai M (2017): Diversity in VP3, NSP3, and NSP4 of rotavirus B detected from Japanese cattle. Infect. Genet. Evol. 49, 97-103. https://doi.org/10.1016/j.meegid.2017.01.003

Johne R, Otto P, Roth B, Lohren U, Belnap D, Reetz J, Trojnar E (2011): Sequence analysis of the VP6-encoding genome segment of avian group F and G rotaviruses. Virology 412, 384-391. https://doi.org/10.1016/j.virol.2011.01.031

Kim HH, Park JG, Matthijnssens J, Kim HJ, Kwon HJ, Son KY, Ryu EH, Kim DS, Lee WS, Kang MI, Yang DK, Lee JH, Park SJ, Cho KO (2013): Pathogenicity of porcine G9P [23] and G9P[7] rotaviruses in piglets. Vet. Microbiol. 166, 123-137. https://doi.org/10.1016/j.vetmic.2013.05.024

Martella V, Banyai K, Matthijnssens J, Buonavoglia C, Ciarlet $M$ (2010): Zoonotic aspects of rotaviruses. Vet. Microbiol. 140, 246-255. https://doi.org/10.1016/j. vetmic.2009.08.028
Matthijnssens J, Ciarlet M, McDonald SM, Attoui H, Banyai K, Brister JR, Buesa J, Esona MD, Estes MK, Gentsch JR, Iturriza-Gomara M, Johne R, Kirkwood CD, Martella V, Mertens PP, Nakagomi O, Parreno V, Rahman M, Ruggeri FM, Saif LJ, Santos N, Steyer A, Taniguchi K, Patton JT, Desselberger U, Van Ranst M (2011): Uniformity of rotavirus strain nomenclature proposed by the Rotavirus Classification Working Group (RCWG). Arch. Virol. 156, 1397-1413. https://doi.org/10.1007/s00705-011-1006-Z

Matthijnssens J, Otto PH, Ciarlet M, Desselberger U, Van Ranst M, Johne R (2012): VP6-sequence-based cutoff values as a criterion for rotavirus species demarcation. Arch. Virol. 157, 1177-1182. https://doi.org/10.1007/s00705012-1273-3

Molinari BL, Possatti F, Lorenzetti E, Alfieri AF, Alfieri AA (2016): Unusual outbreak of post-weaning porcine diarrhea caused by single and mixed infections of rotavirus groups A, B, C, and H. Vet. Microbiol. 193, 125-132. https://doi. org/10.1016/j.vetmic.2016.08.014

Mukherjee A, Dutta D, Ghosh S, Bagchi P, Chattopadhyay S, Nagashima S, Kobayashi N, Dutta P, Krishnan T, Naik, TN, Chawla-Sarkar M (2009): Full genomic analysis of a human group A rotavirus G9P[6] strain from Eastern India provides evidence for porcine-to-human interspecies transmission. Arch. Virol. 154, 733-746. https://doi. org/10.1007/s00705-009-0363-3

Papp H, Laszlo B, Jakab F, Ganesh B, De Grazia S, Matthijnssens J, Ciarlet M, Martella V, Banyai K (2013): Review of group A rotavirus strains reported in swine and cattle. Vet. Microbiol. 165, 190-199. https://doi.org/10.1016/j. vetmic.2013.03.020

Santos N, Volotao EM, Soares CC, Campos GS, Sardi SI, Hoshino Y (2005): Predominance of rotavirus genotype G9 during the 1999, 2000, and 2002 seasons among hospitalized children in the city of Salvador, Bahia, Brazil: implications for future vaccine strategies. J. Clin. Microbiol. 43, 40644069. https://doi.org/10.1128/JCM.43.8.4064-4069.2005

Theuns S, Vyt P, Desmarets LMB, Roukaerts IDM, Heylen E, Zeller M, Matthijnssens J, Nauwynck HJ (2016): Presence and characterization of pig group $\mathrm{A}$ and $\mathrm{C}$ rotaviruses in feces of Belgian diarrheic suckling piglets. Virus Res. 213, 172-183. https://doi.org/10.1016/j.virusres.2015.12.004

Trojnar E, Sachsenroder J, Twardziok S, Reetz J, Otto PH, Johne $\mathrm{R}$ (2013): Identification of an avian group A rotavirus containing a novel VP4 gene with a close relationship to those of mammalian rotaviruses. J. Gen. Virol. 94, 136-142. https://doi.org/10.1099/vir.0.047381-0

Vlasova AN, Amimo JO, Saif LJ (2017): Porcine Rotaviruses: Epidemiology, Immune Responses and Control Strategies. Viruses. 9. https://doi.org/10.3390/v9030048

Wakuda M, Ide T, Sasaki J, Komoto S, Ishii J, Sanekata T, Taniguchi k (2011): Porcine rotavirus closely related to novel group of human rotaviruses. Emerg. Infect. Dis. 17, 1491-1493. https://doi.org/10.3201/edi1708.101466

Woode GN, Bridger J, Hall GA, Jones JM, Jackson G (1976): The isolation of reovirus-like agents (rota-viruses) from acute gastroenteritis of piglets. J. Med. Microbiol. 9, 203-209. https://doi.org/10.1099/00222615-9-2-203 